\title{
Temporal effects of ruminal propionic acid infusion on feeding behavior of Holstein cows in the postpartum period
}

\author{
Gabriela Maldini and Michael S. Allen ${ }^{1}$ \\ Department of Animal Science, Michigan State University, East Lansing 48824
}

\begin{abstract}
The objective of this study was to determine the temporal effects of intraruminal infusion of propionic acid at the initiation of meals on feeding behavior of cows in the postpartum period. Propionic acid derived from ruminal fermentation can reduce energy intake of dairy cows. The suppression of appetite by propionic acid is likely caused by a signal related to the hepatic oxidation of fuels. Greater propionate flux to the liver is expected to result in faster oxidation of acetyl coenzyme A, which can stimulate satiety and reduce feed intake. Therefore, the rate of propionate supply to the liver, within the timeframe of meals, might be an important limitation to feed intake. Our hypothesis was that faster rate of propionate infusion during meals would decrease meal size and feed intake by decreasing the time required to stimulate satiety within a meal. Six ruminally cannulated, multiparous Holstein cows in the postpartum period were used in a duplicated $3 \times 3$ Latin square design experiment balanced for carryover effects. Treatments included control (no infusion) or $1.25 \mathrm{~mol}$ of propionic acid infused over $5 \mathrm{~min}$ (FST) or $15 \mathrm{~min}$ (SLW) at each meal. Infusions were initiated at the conditioned meal at feeding $(1200 \mathrm{~h})$ and were triggered at each spontaneous meal for $22 \mathrm{~h}$. Contrary to our hypothesis, SLW decreased meal size 29\% (0.87 vs. $1.23 \mathrm{~kg}$ of dry matter) compared with FST, and FST decreased meal frequency $27 \%$ ( 8.5 vs. 11.2 per d) compared with SLW. Dry matter intake was similar between FST and SLW, but propionic acid decreased dry matter intake $46 \%$ compared with control. A potential explanation is that FST resulted in greater liver bypass of propionate compared with SLW, extending anaplerosis of the tricarboxylic acid cycle, hepatic oxidation of acetyl coenzyme A, and satiety over a longer time after meals.
\end{abstract}

Received September 18, 2017.

Accepted December 11, 2017.

${ }^{1}$ Corresponding author: allenm@msu.edu
Key words: appetite, feeding behavior, meal size, hepatic oxidation theory

\section{INTRODUCTION}

Maximizing intake in the postpartum period (PP) is critically important to the health, production, and profitability of dairy cows. However, the mechanisms controlling feed intake during the transition period are not completely understood. According to the hepatic oxidation theory, feeding behavior and feed intake are controlled by signals from the liver that are transmitted via hepatic vagal afferents to brain feeding centers (Allen et al., 2009). Increased hepatic oxidation of fuels likely decreases the firing rate of vagus, inhibiting feeding, whereas decreased hepatic oxidation increases its firing rate, stimulating feeding.

The hypophagic effects of propionate are well established, but the mechanism by which it affects feeding is unclear (Allen, 2000). Previous research showed that infusion of propionic acid (PA) decreased feed intake of cows (Choi and Allen, 1999; Stocks and Allen, 2012; Gualdrón-Duarte and Allen, 2017), and that DMI decreased linearly in response to increasing amounts of PA infused (Oba and Allen, 2003b). The rate of PA production in the rumen increases with diet starch content (Bauman et al., 1971; Sutton et al., 2003) and the starch content of diets fed to cows in the PP period varies widely. Furthermore, rumen digestibility of starch varies greatly, ranging from 224 to $942 \mathrm{~g} / \mathrm{kg}$, depending on the starch source (Moharrery et al., 2014). Variation in diet starch content and ruminal digestibility will result in very different rates of PA production, absorption, and flux to the liver. We hypothesized that a greater rate of propionate absorption within meals would stimulate hepatic oxidation and satiety sooner compared with a slower rate of absorption. Our objective was to determine the temporal effects of intraruminal infusion of PA on the feeding behavior of cows in the PP period. We expected that a faster rate of infusion would decrease meal size but increase the time between meals compared with a slower rate of infusion. 


\section{MATERIALS AND METHODS}

The Institutional Animal Care and Use Committee at Michigan State University approved all experimental procedures in this study.

\section{Animals, Housing, and Diets}

Multiparous Holstein cows $(\mathrm{n}=8)$ from the Michigan State University Dairy Cattle Teaching and Research Center were ruminally cannulated at least $40 \mathrm{~d}$ prepartum and used in this experiment. Our goal was to evaluate the effects of treatment on cows during the PP that are in a lipolytic state. Feed intake and health were monitored following parturition. Six healthy cows with the lowest range in days $\mathrm{PP}$ were selected for the experiment and moved to the feeding behavior stalls for an adaptation period of $3 \mathrm{~d}$ before the first infusion day. Cows averaged $13.8 \pm 2.9$ DIM on first day of infusion, and all cows completed the experiment by 22 d PP.

The experimental diet (Table 1) was fed immediately following parturition and contained $16.0 \% \mathrm{CP}, 32.9 \%$ NDF, $26.4 \%$ forage NDF, and $25.0 \%$ starch and consisted of corn silage, alfalfa silage, chopped alfalfa hay, ground corn, soybean meal, soy hulls, and a vitamin and mineral mix formulated to meet requirements according to NRC (2001). Cows were fed once a day (1200 h) at $110 \%$ of expected intake and feed offered was adjusted daily, if needed. Cows were not allowed access to feed between 1000 and $1200 \mathrm{~h}$ each day while orts and the amount offered were weighed for each cow.

\section{Experimental Design and Treatments}

The experimental design was a duplicated $3 \times 3$ Latin square. Cows were blocked by parturition date and randomly assigned to a treatment sequence within a square. Treatments included no infusion (control) and infusion of $1.25 \mathrm{~mol}$ of PA (99.5\%, 0.5 M, Kemin Industries Inc., Des Moines, IA) over 5 (FST) or 15 (SLW) min into the rumen at the conditioned meal and at each spontaneous meal for $22 \mathrm{~h}$. Infusion rates were selected in an attempt to maximize treatment differences while constraining the slow treatment to the expected length of a typical spontaneous meal. Past research in our laboratory with intraruminal infusions of PA used twice this rate at initiation of meals with no adverse effects (Choi and Allen, 1999). Solutions were infused into the rumen using peristaltic pumps (FPU401, Omegaflex Peristaltic Pump, Norwalk, CT) and Tygon tubing that passed through a hole in the cannula plug and was kept in place by stainless-steel hose clamp fixed in each side of the cannula plug. All cows were infused on the same day and a 24-h recovery period following infusion periods was allowed to reduce the potential for carryover effects.

\section{Feeding Behavior}

Feeding behavior was monitored using a computerized data acquisition system (Dado and Allen, 1993) programmed to trigger infusion pumps at the initiation of each new meal according to Choi and Allen (1999) and Bradford and Allen (2007b). Feed manger weights were monitored every $5 \mathrm{~s}$, and when the running standard deviation reached threshold (average running SD greater than $0.9 \mathrm{~kg}$ ), an eating flag was triggered. Infusions were initiated when at least 5 eating flags were triggered within $100 \mathrm{~s}$ to avoid false meals. To prevent mid-meal infusions, the eating flags were required to be triggered less than 13 times in the preceding 7.5 $\mathrm{m}$, otherwise it would be counted as the part of the previous meal. Consecutive infusions began at least 15 min apart under both treatment protocols to prevent potential treatment bias.

Feed disappearance and water consumption were recorded for each cow every $5 \mathrm{~s}$. Feeding behavior data were analyzed to quantify the number, size, length, and time between meals. Hunger ratio was calculated as the weight of meal divided by premeal interval and satiety ratio was calculated as the weight of meal divided by postmeal interval (Forbes, 2007). Triggering infusions based on real-time monitoring of feeding behavior resulted in reasonably good relationship between infusion events and meals, identified by post-hoc analysis. On average, there was a mean of 3 false-positives (infusions

Table 1. Ingredients and nutrient composition of experimental diet (\% of dietary DM except for DM)

\begin{tabular}{lc}
\hline Item & $\%$ \\
\hline Ingredient & \\
Corn silage & 45.0 \\
Ground corn & 10.9 \\
Alfalfa haylage & 21.6 \\
Soybean meal & 10.5 \\
Alfalfa hay & 6.2 \\
Vitamin and mineral mix ${ }^{1}$ & 1.2 \\
Sodium bicarbonate & 0.64 \\
Limestone & 0.67 \\
Nutrient composition & 56.8 \\
DM & 91.3 \\
OM & 25.0 \\
Starch & 32.9 \\
NDF & 26.4 \\
Forage NDF & 16.0 \\
CP & \\
\hline
\end{tabular}

${ }^{1}$ Vitamin and mineral mix contained $25.6 \% \mathrm{NaCl}, 10.0 \% \mathrm{Ca}, 2.0 \% \mathrm{Mg}$, $2.0 \% \mathrm{P}, 30 \mathrm{mg} / \mathrm{kg}$ of $\mathrm{Co}, 506 \mathrm{mg} / \mathrm{kg}$ of Cu, $20 \mathrm{mg} / \mathrm{kg}$ of I, $2,220 \mathrm{mg} /$ $\mathrm{kg}$ of Fe, 2,080 mg/kg of Mn, $15 \mathrm{mg} / \mathrm{kg}$ of Se, 2,030 mg/kg of Zn, 300 $\mathrm{kIU} / \mathrm{kg}$ of vitamin A, $50 \mathrm{kIU} / \mathrm{kg}$ of vitamin $\mathrm{D}$, and $1,500 \mathrm{kIU} / \mathrm{kg}$ of vitamin $\mathrm{E}$. 
without meals) out of a total of 10.5 infusions/cow per $\mathrm{d}$, and 0 false-negatives (meals without infusions)/cow per d with no differences between FST and SLW treatments.

\section{Sample Collection}

All dietary ingredients were sampled daily. Forage samples were analyzed separately for each day and concentrate ingredients were composited across days of the experiment. Orts were weighed and sampled for each cow $(\sim 0.5 \mathrm{~kg})$ at the end of each infusion day. All samples were stored in plastic bags at $-20^{\circ} \mathrm{C}$ until processed. Cows were milked twice daily at 0530 and $1730 \mathrm{~h}$ in their stalls. Milk yield was recorded at each milking, and milk samples were collected from each milking and stored with preservative (Bronopol tablet, D\&F Control Systems, San Ramon, CA) at $4^{\circ} \mathrm{C}$. Milk samples were analyzed by flow cytometer, and Fourier transform spectrometer for fat, true protein, lactose, SCC, and milk urea nitrogen by Michigan DHIA.

Blood samples were collected before and after each infusion period. Blood was sampled from coccygeal vessels and collected into 4 evacuated tubes, 3 containing $\mathrm{K}_{2}$ EDTA and 1 containing potassium oxalate with $\mathrm{NaF}$ as a glycolytic inhibitor, and immediately centrifuged at $3,000 \times g$ for $15 \mathrm{~min}$ at $5^{\circ} \mathrm{C}$. Plasma was harvested and $200 \mu \mathrm{L}$ of benzamidine $(0.25 M)$ was added to $1,000 \mu \mathrm{L}$ of plasma as a protease inhibitor for glucagon analysis. All samples were immediately frozen and kept at $-20^{\circ} \mathrm{C}$ until analysis. Ruminal contents were sampled from 5 sites throughout the rumen and squeezed through a nylon screen (1-mm pore size) to collect the liquid phase at the beginning and end of each infusion period. Ruminal fluid $\mathrm{pH}$ was measured immediately using a portable $\mathrm{pH}$ meter (ATI Orion model 230A, Boston, $\mathrm{MA}$ ), and samples were stored at $-20^{\circ} \mathrm{C}$ until analysis. Fecal samples were collected on rest days (days after infusions) every $8 \mathrm{~h}$ in a 24 -h period $(1400,2200$, and $0600 \mathrm{~h}$ ) and frozen at $-20^{\circ} \mathrm{C}$ for later analysis to determine digestibility and energy concentration of the diet using methods described by Harvatine and Allen (2006).

\section{Analysis of Samples}

Diet ingredients, orts, and fecal samples were dried at $55^{\circ} \mathrm{C}$ in a forced-air oven for $72 \mathrm{~h}$ and ground with a Wiley mill (1-mm screen; Arthur H. Thomas, Philadelphia, PA). Samples were analyzed for ash, NDF, indigestible NDF, CP, and starch. Feces were composited by cow by day on an equal DM basis before analysis. All nutrients are expressed as percentages of DM, determined by drying at $105^{\circ} \mathrm{C}$ in a forced-air oven for at least $8 \mathrm{~h}$. Ash content was determined after $6 \mathrm{~h}$ of oxidation at $500^{\circ} \mathrm{C}$ in a muffle furnace. The NDF was analyzed according to Mertens (2002) with the inclusion of amylase and $\mathrm{Na}$ sulfite. Crude protein was determined according to Hach et al. (1987). Starch was analyzed using an enzymatic method (Karkalas, 1985) after samples were gelatinized with sodium hydroxide; glucose concentration was measured by a glucose oxidase method (Sigma Chemical Co., St. Louis, MO). Indigestible NDF was determined as NDF residue after $240 \mathrm{~h}$ in vitro fermentation (Goering, 1970). Ruminal fluid was collected from a nonpregnant fistulated dry cow and flasks were re-inoculated at $120 \mathrm{~h}$ to ensure microbes were viable. Indigestible NDF was used to estimate fecal output and apparent total-tract digestibility (Cochran et al., 1986). All samples were analyzed for gross energy (GE) by bomb calorimeter according to the manufacturer's instructions (Parr Instrument Inc., Moline, IL). Digestible energy (DE) intake was calculated as GE intake minus GE output in feces. Metabolizable energy from the diet was calculated according to NRC (2001) as ME $(\mathrm{Mcal} / \mathrm{kg})=1.01 \times \mathrm{DE}(\mathrm{Mcal} / \mathrm{kg})-0.45$, based on measured DE. The ME infusion was calculated assuming yields of $365.03 \mathrm{kcal} / \mathrm{mol}$ of propionate (Lebedeva, 1964). The ME intake (MEI) was calculated as MEI $(\mathrm{Mcal} / \mathrm{d})=\mathrm{ME} \times \mathrm{DMI}$ and total MEI $=$ MEI diet + ME infusion.

Plasma samples were analyzed colorimetrically with a microplate reader (SpectraMax Plus 384, Molecular Devices Corp., Sunnyvale, CA) to determine concentrations of metabolites. Commercial kits were used to analyze for plasma concentrations of nonesterified fatty acids (NEFA; NEFA HR kit, Wako Chemicals USA, Richmond, VA), BHB (Stanbio Laboratory, Boerne, TX), and glucose (Glucose oxidase, Sigma Chemical Co.). Glucagon was analyzed by radioimmunoassay (Glucagon kit \#GL-32K, Linco Research, St. Charles, MO). Insulin was determined using an ELISA kit (Mercodia, Uppsala, Sweden). Plasma propionate, acetate, butyrate, and organic acid concentrations were analyzed by HPLC (Waters Corp., Milford, MA) as described by Gualdrón-Duarte and Allen (2017).

\section{Statistical Analysis}

Data were analyzed as a replicated Latin square design using JMP 13.0 software (SAS Institute Inc., Cary, NC). Feeding behavior, intake, milk production, milk components, plasma, and rumen metabolites were analyzed using the following linear model:

$$
Y_{i j k l}=\mu+B_{i}+B_{i}\left(C_{j}\right)+P_{k}+T_{l}+P_{k} \times T_{l}+e_{i j k l},
$$

where $Y_{i j k l}=$ the response variable, $\mu=$ the overall mean, $B_{i}=$ the random effect of block $i, B_{i}\left(C_{j}\right)=$ the 
random effect of cow within block, $P_{k}=$ the fixed effect of period $j, T_{l}=$ the fixed effect of treatment, $P_{k} \times T_{l}$ $=$ the interaction between period and time, and $e_{i j k l}=$ the residual. Orthogonal contrasts were determined for infusions (FST and SLW) versus control and for FST versus SLW infusions. Significance was declared at $P \leq$ 0.05 and tendency for significance at $P \leq 0.10$.

\section{RESULTS}

\section{Feed Intake and Feeding Behavior}

Results for feed intake and feeding behavior are reported in Table 2. The PA treatments decreased meal size compared with control (1.59 vs. $1.05 \mathrm{~kg}$ of DM, $P$ $<0.01$ ), and SLW decreased meal size $29 \%$ compared with FST (1.23 vs. $0.87 \mathrm{~kg}$ of $\mathrm{DM}, P=0.01)$. The PA treatments also decreased meal frequency compared with control (12.0 vs. 9.8 meals $/ \mathrm{d}, P=0.01)$ and FST decreased meal frequency $24 \%$ compared with SLW (8.5 vs. 11.2 meals/d, $P=0.01$ ). Meal length was not affected by treatment $(23.0 \mathrm{~m})$; however, PA treatments increased intermeal interval compared with control (88.9 vs. $120.9 \mathrm{~m}, P<0.01)$ and FST increased intermeal interval 35\% compared with SLW (139 vs. $103 \mathrm{~m}, P=0.01)$. Both PA treatments decreased DMI $46 \%$ compared with control (18.6 vs. $10.2 \mathrm{~kg} / \mathrm{d}, P<$ $0.01)$ with similar effects for FST and SLW treatments (10.4 vs. $10.0 \mathrm{~kg}$ of DM, $P=0.74)$.

The amount of PA infused $(\sim 36.4 \mathrm{~mol} / \mathrm{d})$ provided 13.3 Mcal of ME/d and did not differ $(P=0.35)$ between FST and SLW. When the ME from the treat- ment infusions was added to the MEI from the diet, PA tended to decrease total MEI $13 \%$ per day (41.7 vs. $36.9 \mathrm{Mcal} / \mathrm{d}, P=0.10)$ and effects of FST and SLW were similar ( 36.0 vs. $37.8 \mathrm{Mcal} / \mathrm{d}, P=0.54)$. The PA infusion decreased hunger ratio $(0.037$ vs. $0.013, P<$ $0.01)$ and tended to decrease satiety ratio (0.045 vs. $0.022, P=0.07)$ compared with control, but no differences were observed for FST versus SLW infusion treatments $(P>0.60)$.

The PA treatments decreased water intake compared with control ( 84.4 vs. $26.8 \mathrm{~L} / \mathrm{d} ; P<0.01)$ by decreasing drinking frequency (12.0 vs. 4.8 bouts, $P<0.01)$, but effects of FST and SLW were similar for both water intake $(29.3$ vs. $24.3 \mathrm{~L} / \mathrm{d}, P=0.7)$ and drinking frequency ( 5.0 vs. 4.7 bouts, $P=0.9$ ). When the amount of infusate from the treatments was added to the daily water intake, PA decreased overall liquid daily intake $34 \%$ when compared with control $(84.4$ vs. $55.8 \mathrm{~L} / \mathrm{d}, P$ $=0.02)$.

\section{Milk Production and Components}

Treatments did not affect yields of milk $(39.1 \mathrm{~kg} / \mathrm{d})$, protein $(0.55 \mathrm{~kg} / \mathrm{d})$, fat $(1.03 \mathrm{~kg} / \mathrm{d})$, lactose $(0.93 \mathrm{~kg} / \mathrm{d})$, SNF $(1.09 \mathrm{~kg} / \mathrm{d}), \operatorname{SSC}(43.0 \times 1,000 / \mathrm{mL})$, or MUN (11.47 mg/dL); all $P>0.2$ (data not shown).

\section{Plasma Metabolites and Rumen Fluid}

Results for plasma metabolites are reported in Table 3 . The PA infusions increased blood glucose concentration compared with control $(11.5$ vs. $-0.29 \mathrm{mg} / \mathrm{dL}, P$

Table 2. Effects of intraruminal infusion of propionic acid at meals over 5 (FST) or 15 (SLW) min compared with the control on feeding behavior and energy intake for cows in the immediate postpartum period

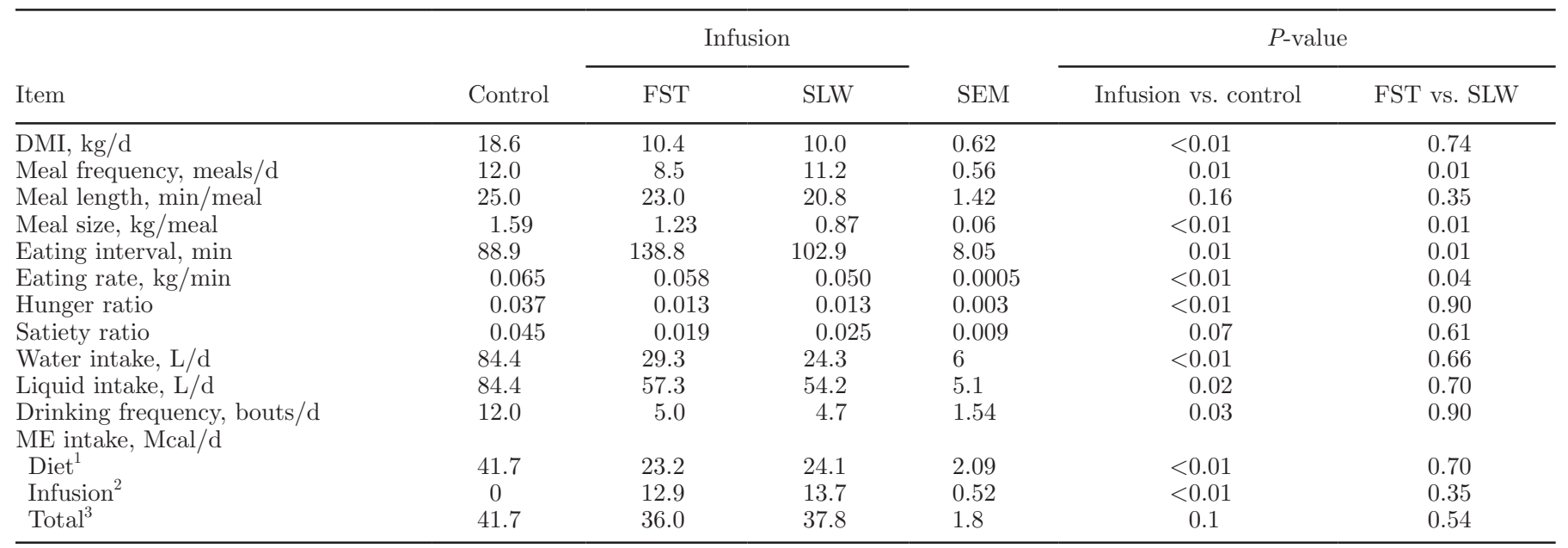

${ }^{1} \mathrm{ME}$ intake from the diet was calculated according to NRC $(2001)$. ME $(\mathrm{Mcal} / \mathrm{kg})=1.01 \times$ digestible energy $(\mathrm{Mcal} / \mathrm{kg})-0.45$, based on actual digestibility of diets. ME intake $(\mathrm{Mcal} / \mathrm{d})=\mathrm{ME}(\mathrm{Mcal} / \mathrm{kg}) \times \mathrm{DMI}$.

${ }^{2} \mathrm{ME}$ intake from the infusion was based on energy density of $0.365 \mathrm{Mcal} / \mathrm{mol}$ of ME (Lebedeva, 1964) for propionic acid.

${ }^{3}$ Total ME intake $=$ ME intake diet + ME infusion. 
Table 3. Effects of intraruminal infusion of propionic acid at meals over 5 (FST) or 15 (SLW) min compared with control on plasma metabolites and hormones for cows in the immediate postpartum period

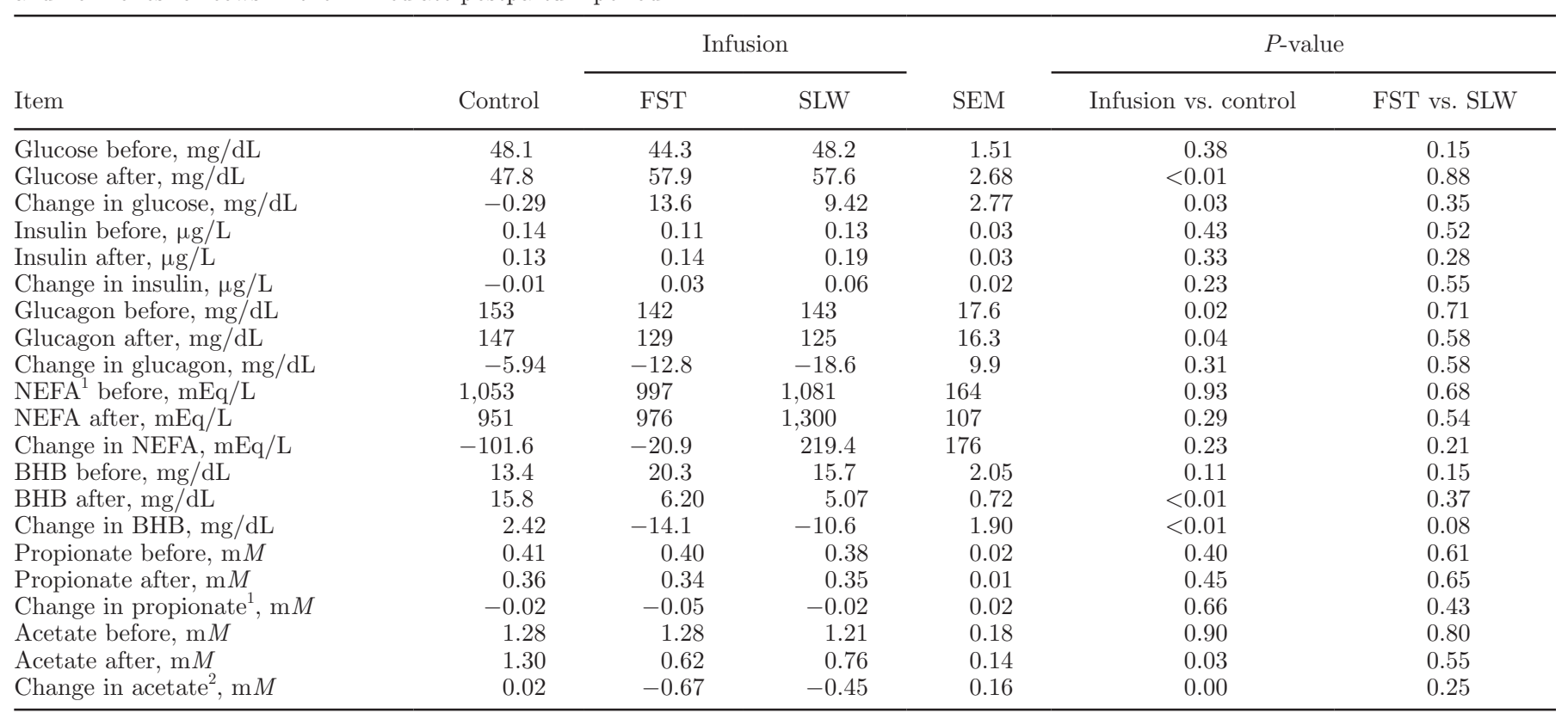

${ }^{1} \mathrm{NEFA}=$ nonesterified fatty acids.

${ }^{2}$ Cow and block effect treated as fixed.

$=0.03)$, but effects of rate of infusion did not differ $(P=0.35)$. Plasma concentrations of insulin, glucagon, NEFA, and propionate were not affected by treatment (all $P>0.24$ ), but PA decreased BHB concentration compared with control $(2.4$ vs. $-12.4 \mathrm{mg} / \mathrm{dL}, P<$ $0.01)$ and the reduction tended to be greater for FST than SLW ( -14.1 vs. $-10.6 \mathrm{mg} / \mathrm{dL}, P=0.08)$. The PA treatments decreased plasma acetate $(0.02$ vs. -0.56 $\mathrm{m} M, P<0.01)$ compared with control, but the effects of rate of infusion were similar $(P=0.25)$.

Results for rumen fluid $\mathrm{pH}$ and organic acids are reported in Table 4. The PA treatments increased PA concentration (2.1 vs. $14.6 \mathrm{~m} M, P=0.04)$ and $\mathrm{pH}(-0.21$ vs. $0.26, P=0.04)$ compared with control with no difference detected between FST and SLW treatments $(P \geq 0.20)$. The PA treatments decreased concentrations of acetic acid (10.0 vs. $-16.4 \mathrm{mM}, P<$ $0.01)$ and butyric acid (3.10 vs. $-3.99 \mathrm{~m} M, P<0.01)$ compared with control, and effects were similar for FST and SLW treatments $(P>0.3)$. Concentration of lactic acid was not affected by treatment $(P=0.44)$.

\section{DISCUSSION}

Compared with control, both infusion treatments reduced the size and frequency of meals, resulting in a $46 \%$ reduction in DMI. It is unlikely that the decrease in DMI by PA infusion was from additional energy supplied by the infusions because total MEI tended to be reduced by PA treatments. The reduction in DMI and MEI by PA infusion was expected and consistent with studies previously reviewed (Allen, 2000; Allen et al., 2009). Suppression of DMI by PA was likely due to hypophagic signals from increased hepatic oxidation of fuels (Langhans and Scharrer, 1992; Friedman, 1995). The decreased hunger ratio for PA infusions indicates that PA treatments decreased hunger compared with control. Although the infusion treatments affected both the size and frequency of meals, the effects for FST and SLW were opposite and compensated for each other, decreasing DMI equally.

We hypothesized that faster PA infusion within meals would decrease meal size and increase meal frequency. The FST treatment was expected to increase anaplerosis and stimulate oxidation of acetyl CoA in the tricarboxylic acid (TCA) cycle sooner, resulting in smaller meal size compared with SLW. Because meals were expected to be smaller, we also expected the intermeal interval to decrease for FST compared with SLW, increasing meal frequency. However, contrary to our hypothesis, FST increased meal size and decreased meal frequency compared with SLW.

The greater flux of propionate supplied by FST might have saturated the pathway for propionate metabolism sooner, resulting in a lower first-pass extraction by the liver compared with SLW. Propionate is rapidly (Reynolds et al., 2003) and very efficiently (Bell and Bauman, 1997) extracted from the blood by the liver. However, 
propionate metabolism in hepatocytes can be saturated (Ali and Jois, 1997) and propionate not taken up by the liver would enter the general circulation. Because propionate metabolism by other organs in the ruminant is minimal (Brockman, 2005), propionate bypassing the liver would be expected to extend anaplerosis of the TCA cycle and hepatic oxidation of acetyl CoA over time, increasing intermeal interval and decreasing meal frequency. Propionate is a very effective TCA anaplerotic precursor, even at low concentrations (Brunengraber and Roe, 2006). Accordingly, FST increased intermeal interval $35 \%$ and decreased meal frequency $24 \%$ compared with SLW.

Hepatic extraction of propionate is by activation to propionyl $\mathrm{CoA}$, which is then trapped in the mitochondria (Ricks and Cook, 1981). Although propionyl-CoA synthetase activity is high in ruminant hepatocytes (Ricks and Cook, 1981; Demigné et al., 1986), plasma propionate concentration increased linearly from 0.19 to $0.34 \mathrm{~m} M$ when propionate was infused intraruminally from 0 to $1.3 \mathrm{~mol} / \mathrm{h}$ for $18 \mathrm{~h}$ for cows in the $\mathrm{PP}$ period (Oba and Allen, 2003a) indicating limitations to activation to propionyl-CoA. However, bottlenecks can also occur at other reactions for entry into, or within the TCA cycle. For instance, the malate dehydrogenase reaction is inhibited when NADH is elevated, potentially causing an accumulation and release of malate into the blood and allowing for extended anaplerosis if metabolized by the liver later.

Both infusion treatments reduced meal size compared with control, but the reduction in meal size for SLW compared with FST is likely because saturation of the propionate metabolism pathway was reduced for SLW compared with FST, allowing greater first-pass pro- pionate extraction with less propionate bypass during the infusion. Greater anaplerosis potentially increased oxaloacetate available for the citrate synthase reaction, facilitating the entry and oxidation of acetyl CoA in the TCA cycle and causing satiety sooner.

Meal size and frequency were not affected by rate of PA infusion in a similar experiment in our laboratory (Bradford and Allen, 2007a) likely because cows were later in lactation (51 DIM) and in a different physiological state. Propionate was more hypophagic for cows in the PP period than later in lactation (Oba and Allen, 2003b), likely because cows in the PP period are in a lipolytic state with greater availability of acetyl CoA for entry into the TCA cycle (Piantoni et al., 2015).

The increased plasma glucose concentration by PA treatments was expected because propionate is the major glucose precursor in ruminants (Lemosquet et al., 2009) and is consistent with previous experiments (Oba and Allen, 2003a; Stocks and Allen, 2012). Increased PA concentration in the rumen by PA treatments was expected, whereas no effect of treatment on plasma propionate concentration was likely because of extraction by the liver and because blood samples were taken at the beginning and end of the infusion period, and not over time following infusions. Whereas plasma propionate concentration likely changed during infusions, possibly affecting plasma insulin, glucagon, and NEFA concentrations within a day, lack of treatment effects on changes in their plasma concentrations were likely due to the long time $(22 \mathrm{~h})$ between sampling and the time between the last infusion and sampling at the end of the infusion period. We chose not to sample throughout the infusion period to prevent interference with the natural feeding behavior of the cows. The reductions

Table 4. Effects of intraruminal infusion of propionic acid at meals over 5 (FST) or 15 (SLW) min compared with control on ruminal pH and organic acids for cows in the immediate postpartum period

\begin{tabular}{|c|c|c|c|c|c|c|}
\hline \multirow[b]{2}{*}{ Ruminal fluid } & \multirow[b]{2}{*}{ Control } & \multicolumn{2}{|c|}{ Infusion } & \multirow[b]{2}{*}{ SEM } & \multicolumn{2}{|c|}{$P$-value } \\
\hline & & FST & SLW & & Infusion vs. control & FST vs. SLW \\
\hline $\mathrm{pH}$ after infusions & 6.15 & 6.71 & 6.56 & 0.09 & $<0.01$ & 0.09 \\
\hline Change in $\mathrm{pH}$ & -0.21 & 0.35 & 0.17 & 0.16 & 0.03 & 0.34 \\
\hline Propionic acid before, $\mathrm{m} M$ & 22.2 & 19.5 & 21.7 & 2.73 & 0.07 & 0.04 \\
\hline Propionic acid after, $\mathrm{m} M$ & 24.3 & 30.5 & 40.1 & 3.90 & 0.06 & 0.11 \\
\hline Lactic acid after, $\mathrm{m} M$ & 0.17 & 0.17 & 0.05 & 0.03 & 0.51 & 0.28 \\
\hline Change in lactic acid, $\mathrm{m} M$ & -0.9 & -0.20 & -0.5 & 0.05 & 0.31 & 0.53 \\
\hline Acetic acid before, $\mathrm{m} M$ & 58.1 & 59.5 & 58.3 & 5.38 & 0.86 & 0.82 \\
\hline Acetic acid after, $\mathrm{m} M$ & 68.1 & 41.1 & 44.0 & 1.70 & $<0.01$ & 0.15 \\
\hline Change in acetic acid, $\mathrm{m} M$ & 10.0 & -18.4 & -14.3 & 4.2 & $<0.01$ & 0.40 \\
\hline Butyric acid before, $\mathrm{m} M$ & 8.65 & 9.73 & 8.88 & 1.33 & 0.63 & 0.59 \\
\hline Butyric acid after, ${ }^{1} \mathrm{~m} M$ & 11.8 & 4.97 & 5.73 & 0.25 & $<0.01$ & 0.13 \\
\hline
\end{tabular}

${ }^{1}$ Cow and block effect treated as fixed. 
in ruminal acetate and butyrate concentrations and plasma acetate concentration by the PA treatments were consistent with the reduction in DMI and substrate available for ruminal fermentation. Whereas PA infusion might be expected to decrease ruminal $\mathrm{pH}$ compared with control, the opposite occurred likely because PA reduced DMI. In addition, ruminal $\mathrm{pH}$ was only measured at the beginning and end of each infusion day and not during infusions.

The reduction in plasma $\mathrm{BHB}$ concentration by the PA treatments is consistent with greater oxidation of acetyl CoA in the TCA cycle because plasma NEFA concentration was not affected by treatment. In this study FST tended to decrease BHB compared with SLW, possibly because of extended anaplerosis and oxidation of acetyl CoA from bypassed propionate. Another possible explanation is that the PA treatments decreased ketogenesis because propionate decreases expression of HMG CoA synthetase (Bush and Milligan, 2011).

The lack of treatment effect for yields of milk and milk components is likely because of the short duration of this experiment. Although treatments increased the amount of propionate potentially available for gluconeogenesis, DMI was reduced and a longer period of evaluation would be needed for a change in milk yield or composition to be detected.

Rate and amount of PA production in the rumen is highly variable and easily manipulated by altering diet starch concentration and fermentability (Allen and Piantoni, 2014). However, diet starch concentration and fermentability affect both the rate of PA production and the amount of PA produced. Starch sources with greater rates of fermentation generally increase both rate and amount of PA produced. We conducted this experiment to try to determine the effects of rate of PA production independent of the amount produced per day.

Caution should be used when applying these results for diet formulation. Although rate of PA infusion did not affect DMI of cows in the PP period in this experiment, our cows were housed in tiestalls with access to the ration throughout the day and did not compete with other cows for feed, allowing greater flexibility to compensate for reduced meal size. Altering the content and fermentability of starch in diets might have different effects for cows housed in groups compared with cows housed individually because competition among cows for feed might limit the opportunity to compensate for reduced meal size.

The amount of PA infused at each meal in this experiment might have affected our results. We chose to infuse $1.25 \mathrm{~mol}$ of PA at each meal for this experiment, which is almost half of the expected ruminal pool size of PA for a cow with $80 \mathrm{~L}$ of rumen liquid volume and a PA concentration of $30 \mathrm{mM}$. Production rates of PA in the rumen for cows consuming normal or low-roughage diets have been reported to range from 13 to $31 \mathrm{~mol} / \mathrm{d}$ for cows consuming $\sim 15 \mathrm{~kg}$ of DM/d (Bauman et al., 1971 ) and 17 to $36 \mathrm{~mol} / \mathrm{d}$ for cows consuming $\sim 12 \mathrm{~kg}$ of DM/d (Sutton et al., 2003). In previous experiments in our laboratory, cows in the PP period consumed $\sim 20$ $\mathrm{kg}$ of DM/d with 10 to 12 meals per day. Therefore, the amount of PA produced during each meal is likely greater than the amount we infused per meal. The experiments that measured production rates of PA did so over much longer periods of time compared with the length of meals. What is not known is the variation in PA production within the timeframe of meals. Because the amount of PA infused at each meal had a large effect on DMI for both treatments, infusion of a lower dose of PA over 5 or 15 min might have different results and should be evaluated. In addition, evaluation of intermediates of propionate metabolism over time after the start of infusion will help identify bottlenecks to propionate metabolism and should be evaluated.

\section{CONCLUSIONS}

A greater rate of PA infusion into the rumen of cows in the PP resulted in greater meal size and decreased intermeal interval, contrary to our hypothesis. A possible explanation is that a faster rate of propionate supply and absorption saturated the pathway for propionate metabolism in the liver, resulting in less stimulation of hepatic oxidation during meals, larger meals, and longer time between meals. Diets for dairy cows vary greatly in the type and temporal pattern of fuels absorbed and although glucose precursors must be provided to support milk production, careful consideration must be given to the fermentability of the ingredients used when formulating rations to maximize energy intake. More research is needed to determine the mechanisms by which temporal absorption of fuels affect feeding behavior and energy intake of cows, particularly during the PP period. Potential bottlenecks for propionate metabolism in the liver should be explored further.

\section{ACKNOWLEDGMENTS}

We gratefully acknowledge financial support for this project by USDA National Research Initiative Competitive Grant no. 2014-67015-21708 to M. S. A., and from CAPES-Brazilian Federal Agency for Support and Evaluation of Graduate Education within the Ministry of Education of Brazil to G. M. We also thank D. G. Main, R. Longuski, K. Kennedy, L. G. Duarte, R. Albornoz, and R. West (all from Michigan 
State University), as well as the staff of the Michigan State University Dairy Cattle Field Laboratory (East Lansing) for their assistance in this experiment, and Kemin Animal Nutrition and Health (Des Moines, IA) for supplying the propionic acid.

\section{REFERENCES}

Ali, A. M., and M. Jois. 1997. Uptake and metabolism of propionate in the liver isolated from sheep treated with glucagon. Br. J. Nutr. 77:783-793. https://doi.org/10.1079/BJN19970075.

Allen, M. S. 2000. Effects of diet on short-term regulation of feed intake by lactating dairy cattle. J. Dairy Sci. 83:1598-1624. https:// doi.org/10.3168/jds.S0022-0302(00)75030-2.

Allen, M. S., B. J. Bradford, and M. Oba. 2009. Board-Invited Review: The hepatic oxidation theory of the control of feed intake and its application to ruminants. J. Anim. Sci. 87:3317-3334. https://doi .org/10.2527/jas.2009-1779.

Allen, M. S., and P. Piantoni. 2014. Carbohydrate nutrition. Vet. Clin. North Am. Food Anim. Pract. 30:577-597. https://doi.org/10 $.1016 /$ j.cvfa.2014.07.004

Bauman, D. E., C. L. Davis, and H. F. Bucholtz. 1971. Propionate production in the rumen of cows fed either a control or highgrain, low-fiber diet. J. Dairy Sci. 54:1282-1287. https://doi.org/ 10.3168/jds.S0022-0302(71)86021-6.

Bell, A. W., and D. E. Bauman. 1997. Adaptations of glucose metabolism during pregnancy and lactation. J. Mammary Gland Biol. Neoplasia 2:265-278. https://doi.org/10.1023/A:1026336505343.

Bradford, B. J., and M. S. Allen. 2007a. Short communication: Rate of propionate infusion within meals does not influence feeding behavior. J. Dairy Sci. 90:2305-2308. https://doi.org/10.3168/jds.2006 -744 .

Bradford, B. J., and M. S. Allen. 2007b. Depression in feed intake by a highly fermentable diet is related to plasma insulin concentration and insulin response to glucose infusion. J. Dairy Sci. 90:38383845. https://doi.org/10.3168/jds.2007-0086.

Brockman, R. P. 2005. Glucose and short-chain fatty acid metabolism. Pages 291-310 in Quantitative Aspects of Ruminant Digestion and Metabolism. CAB International, Wallingford, UK.

Brunengraber, H., and C. R. Roe. 2006. Anaplerotic molecules: Current and future. J. Inherit. Metab. Dis. 29:327-331. https://doi .org/10.1007/s10545-006-0320-1.

Bush, R. S., and L. P. Milligan. 2011. Study of the mechanism of inhibition of ketogenesis by propionate in bovine liver. Can. J. Anim. Sci. 51:121-127. https://doi.org/10.4141/cjas71-016.

Choi, B. R., and M. S. Allen. 1999. Intake regulation by volatile fatty acids and physical fill. S. Afr. J. Anim. Sci. 29:40-41.

Cochran, R. C., D. C. Adams, J. D. Wallace, and M. L. Galyean. 1986. Predicting digestibility of different diets with internal markers: Evaluation of four potential markers. J. Anim. Sci. 63:1476-1483. https://doi.org/10.2527/jas1986.6351476x.

Dado, R. G., and M. S. Allen. 1993. Continuous computer acquisition of feed and water intakes, chewing, reticular motility, and ruminal pH of cattle. J. Dairy Sci. 76:1589-1600. https://doi.org/10.3168/ jds.S0022-0302(93)77492-5.

Demigné, C., C. Yacoub, C. Rémésy, and P. Fafournoux. 1986. Propionate and butyrate metabolism in rat or sheep hepatocytes. Biochim. Biophys. Acta 875:535-542. https://doi.org/10.1016/0005 -2760(86)90074-3.

Forbes, J. M. 2007. Voluntary food intake and diet selection in farm animals. 2nd ed. CAB International, Wallingford, UK.

Friedman, M. I. 1995. Control of energy intake by energy metabolism. Am. J. Clin. Nutr. 62:1096S-1100S.

Goering, H. K., and P. J. Van Soest. 1970. Forage fiber analyses (Apparatus, Reagents, Procedures, And Some Applications) Agric. Handbook No. 379. ARS-USDA, Washington, DC.
Gualdrón-Duarte, L. B., and M. S. Allen. 2017. Increased anaplerosis of the tricarboxylic acid cycle decreased meal size and energy intake of cows in the postpartum period. J. Dairy Sci. 100:44254434. https://doi.org/10.3168/jds.2016-12104.

Hach, C. C., B. K. Bowden, A. B. Kopelove, and S. V. Brayton. 1987. More powerful peroxide Kjeldahl digestion method. J. Assoc. Off. Anal. Chem. 70:783-787.

Harvatine, K. J., and M. S. Allen. 2006. Effects of fatty acid supplements on ruminal and total tract nutrient digestion in lactating dairy cows. J. Dairy Sci. 89:1092-1103. https://doi.org/10.3168/ jds.S0022-0302(06)72177-4.

Karkalas, J. 1985. An improved enzymic method for the determination of native and modified starch. J. Sci. Food Agric. 36:1019-1027. https://doi.org/10.1002/jsfa.2740361018.

Langhans, W., and E. Scharrer. 1992. Metabolic Control of Eating. Pages 1-67 in Metabolic Control of Eating, Energy Expenditure and the Bioenergetics of Obesity. Vol. 70. Karger Publishers. https://doi.org/10.1159/000421670.

Lebedeva, N. D. 1964. Heats of combustion of monocarboxylic acids. Russ. J. Phys. Chem. (Engl. Transl.). 38:1435-1437.

Lemosquet, S., G. Raggio, G. E. Lobley, H. Rulquin, J. Guinard-Flament, and H. Lapierre. 2009. Whole-body glucose metabolism and mammary energetic nutrient metabolism in lactating dairy cows receiving digestive infusions of casein and propionic acid. J. Dairy Sci. 92:6068-6082. https://doi.org/10.3168/jds.2009-2018.

Mertens, D. R. 2002. Gravimetric determination of amylase-treated neutral detergent fiber in feeds with refluxing in beakers or crucibles: collaborative study. J. AOAC Int. 85:1217-1240.

Moharrery, A., M. Larsen, and M. R. Weisbjerg. 2014. Starch digestion in the rumen, small intestine, and hind gut of dairy cows-A meta-analysis. Anim. Feed Sci. Technol. 192:1-14. https://doi.org/ 10.1016/j.anifeedsci.2014.03.001.

NRC. 2001. Nutrient Requirements of Dairy Cattle. 7th rev. ed. Natl. Acad. Press, Washington, DC.

Oba, M., and M. S. Allen. 2003a. Intraruminal infusion of propionate alters feeding behavior and decreases energy intake of lactating dairy cows. J. Nutr. 133:1094-1099.

Oba, M., and M. S. Allen. 2003b. Dose-response effects of intraruminal infusion of propionate on feeding behavior of lactating cows in early or midlactation. J. Dairy Sci. 86:2922-2931. https://doi.org/ 10.3168/jds.S0022-0302(03)73889-2.

Piantoni, P., C. M. Ylioja, and M. S. Allen. 2015. Feed intake is related to changes in plasma nonesterified fatty acid concentration and hepatic acetyl CoA content following feeding in lactating dairy cows. J. Dairy Sci. 98:6839-6847. https://doi.org/10.3168/jds.2014 -9085 .

Reynolds, C. K., P. C. Aikman, B. Lupoli, D. J. Humphries, and D. E. Beever. 2003. Splanchnic metabolism of dairy cows during the transition from late gestation through early lactation. J. Dairy Sci 86:1201-1217. https://doi.org/10.3168/jds.S0022-0302(03)73704 -7 .

Ricks, C. A., and R. M. Cook. 1981. Regulation of volatile fatty acid uptake by mitochondrial acyl CoA synthetases of bovine liver. J. Dairy Sci. 64:2324-2335. https://doi.org/10.3168/jds.S0022 $-0302(81) 82854-8$.

Stocks, S. E., and M. S. Allen. 2012. Hypophagic effects of propionate increase with elevated hepatic acetyl coenzyme A concentration for cows in the early postpartum period. J. Dairy Sci. 95:32593268. https://doi.org/10.3168/jds.2011-4991.

Sutton, J. D., M. S. Dhanoa, S. V. Morant, J. France, D. J. Napper, and E. Schuller. 2003. Rates of production of acetate, propionate, and butyrate in the rumen of lactating dairy cows given normal and low-roughage diets. J. Dairy Sci. 86:3620-3633. https://doi .org/10.3168/jds.S0022-0302(03)73968-X. 